\title{
Caracterização fenotípica, produção de biofilme e resistência aos antimicrobianos em isolados de Staphylococcus spp. obtidos de casos de mastite em bovinos e bubalinos ${ }^{1}$
}

\author{
Gabriela Guimarães ${ }^{2}$, Chirles A. de França ${ }^{3}$, Fernanda dos S. Krug², Rodolfo de M. \\ Peixoto $^{4}$, Carina da C. Krewer ${ }^{3}$, Andrea M. Lazzari ${ }^{2}$ e Mateus M. da Costa ${ }^{3 *}$
}

\begin{abstract}
Guimarães G., França C.A., Krug F.S., Peixoto R.M., Krewer C.C., Lazzari A.M. \& Costa M.M. 2012. [Phemotypic characterization, biofilm production and antimicrobial resistance of Staphylococcus spp. Isolates from cattle and buffaloes mastitis.] Caracterização fenotípica, produção de biofilme e caracterização da resistência aos antimicrobianos em isolados de Staphylococcus spp. obtidos de casos de mastite em bovinos e bubalinos. Pesquisa Veterinária Brasileira 32(12):1219-1224. Universidade Federal do Vale do São Francisco, Campus Ciências Agrárias, Rodov. BR 407 Km 12, Lote 543, Projeto de Irrigação Senador Nilo Coelho s/n, Petrolina, PE 56300-990, Brazil.E-mail: mateus.costa@univasf.edu.br

The aim of the present study was to evaluate the antimicrobial susceptibility pattern and to perform the phenotypic and genotypic characterization of the Staphylococcus spp. isolates from mastitis cases in cattle $(n=30)$ and buffaloes $(n=30)$. The susceptibility to antimicrobial drugs was performed by disk diffusion test and the presence of efflux pump was evaluated in Mueller Hinton (MH) Agar supplemented with ethidium bromide as well as by detection of $m s r A$ gene. Similarly, the PCR technique was done to detect mecA, blaZ and ermA, B e C genes, that were related after with the presence of antimicrobial resistance in disk diffusion test. The formation of biofilm was characterized using Congo Red Agar (CRA), microplate adherence and detection of icaD gene. Staphylococcus spp. isolates shown high antimicrobial susceptibility in disk diffusion test. The multidrug resistance (MDR) rate ranged from 0 and 0,5 . In the efflux pump test, $26.7 \%$ of Staphylococcus spp. strains were positive in phenotypic method and $6.7 \%$ in PCR for msrA gene. The erm, mecA and blaZ genes were detected in $1.7 \%, 6.7 \%$ and $11.7 \%$ of Staphylococcus spp. strains respectively. In biofilm production tests, $23.3 \%$ of the samples were positive in CRA, $50 \%$ in microplate adherence test and $8.3 \%$ in icaD gene PCR. The cattle isolates were less sensitive to antimicrobial drugs when compared to the buffaloes ones. The characterization of these isolates is very important to guide a successful antimicrobial therapy. The biofilm presence in the isolates may be associated with other factors besides antimicrobial resistance.
\end{abstract}

INDEX TERMS: Mastitis, dairy cattle, buffalo, Staphylococcus spp., resistance genes.

RESUMO.- No presente estudo, objetivou-se avaliar a suscetibilidade aos principais antimicrobianos e realizar uma caracterização fenotípica e genotípica de isolados de Staphy-

\footnotetext{
${ }^{1}$ Recebido em 10 de abril de 2012.

Aceito para publicação em 14 de agosto de 2012.

${ }^{2}$ União Pioneira de Integração Social (UPIS), Campus II, Faz. Lagoa Bonita, BR 020 Km 335, Planaltina, DF 13350-980, Brasil.

${ }^{3}$ Universidade Federal do Vale do São Francisco, Campus Ciências Agrárias, Rod. BR $407 \mathrm{Km} \mathrm{12,} \mathrm{Lote} \mathrm{543,} \mathrm{Projeto} \mathrm{de} \mathrm{Irrigação} \mathrm{Senador} \mathrm{Nilo} \mathrm{Co-}$ elho s/n, Petrolina, PE 56300-990, Brasil. *Autor para correspondência: mateus.costa@univasf.edu.br

${ }^{4}$ Instituto Federal de Educação, Ciência e Tecnologia do Sertão Pernambucano, Campus Floresta, Rua Projetada s/n, Caetano II, Floresta, PE 56400-000, Brasil.
}

lococcus spp. obtidos de casos de mastite em vacas $(\mathrm{n}=30)$ e búfalas $(\mathrm{n}=30)$. A suscetibilidade foi avaliada pela técnica de disco-difusão e a presença de bomba de efluxo foi avaliada utilizando-se Ágar Mueller Hinton (MH) adicionado de brometo de etídeo e pesquisa do gene $m s r$. Pela técnica da Reação em Cadeia da Polimerase (PCR) ainda foram identificados os genes mecA, blaZ e ermA, B e C, que posteriormente foram associados com os métodos fenotípicos para a identificação de resistência a antimicrobianos. A caracterização da formação de biofilme foi realizada utilizandose os métodos Ágar Vermelho Congo (CRA), Aderência em Placa e a identificação do gene icaD. Pelo método de discodifusão, os Staphylococcus spp. apresentaram alta sensibili- 
dade aos antimicrobianos. 0 índice de resistência múltipla aos antimicrobianos (IRMA) apresentou variação de 0 a 0,5 . Na pesquisa de bomba de efluxo, $26,7 \%$ das amostras foram positivas ao método fenotípico e $6,7 \%$ ao método genotípico (gene $m s r A$ ). Os genes erm, mecA e blaZ foram detectados, respectivamente, em $1,7 \%, 6,7 \%$ e $11,7 \%$ das amostras de Staphylococcus spp. Na produção de biofilme, $23,3 \%$ dos isolados foram considerados positivos no CRA, $50,0 \%$ na Aderência em Placas e $8,3 \%$ na PCR pela detecção do gene icaD. Observou-se que os isolados obtidos de amostras bovinas apresentaram uma menor sensibilidade aos antimicrobianos no teste de disco-difusão quando comparados com as amostras bubalinas. A caracterização destes isolados é importante para orientar uma antibioticoterapia bem planejada. A presença de biofilme nos isolados pode estar associada a outros fatores que não a resistência às drogas antimicrobianas.

TERMOS DE INDEXAÇÃO: Mastite, bovino leiteiro, bubalino, Staphylococcus spp., genes de resistência.

\section{INTRODUÇÃo}

A mastite continua sendo um grande problema para a pecuária leiteira, apesar das várias pesquisas voltadas para o diagnóstico e controle desta enfermidade (Lazzari et al. 2002, Oliveira et al. 2002, Freitas et al. 2005, Medeiros et al. 2011). Embora possa ser ocasionada por inúmeros patógenos, bactérias do gênero Staphylococcus spp. são reconhecidas como os agentes etiológicos mais isolados dos casos de mastite (De Vliegher et al. 2012).

0 uso inadequado de antimicrobianos no tratamento dessa enfermidade tem desencadeado a seleção de bactérias resistentes (Vermelho et al. 2007). Os mecanismos de aquisição de resistência podem ser classificados em dois grupos: mutação em genes presentes no cromossomo bacteriano ou aquisição de genes de resistência de outros micro-organismos, através dos processos de transdução, transformação ou conjugação (Ito et al. 2003).

A resistência ao grupo dos beta-lactâmicos é oriunda principalmente de dois genes, mecA e blaz, sendo o gene $m e c A$ responsável pela codificação de uma proteína ligadora de penicilina (PBP) alterada denominada de PBP-2A que tem reduzida afinidade aos beta-lactâmicos (Bignardi et al. 1996). 0 mecanismo de resistência promovido pelo gene blaZ se baseia na inativação por meio da enzima beta-lactamase ou penicilase. Essas enzimas utilizam o anel beta-lactâmico das penicilinas como substrato, degradando-o por hidrólise. Mais de $400 \beta$-lactamases já foram descritas (Li et al. 2007).

A resistência dos Staphylococcus spp. a macrolídeos, lincosamida e estreptogramina B é baseada na expressão de $\mathrm{N}$-metiltransferases que realizam a metilação e dimetilação de um resíduo de adenina no domínio funcional do rRNA 23S, levando a redução da ligação desses fármacos ao sítio alvo, na subunidade 50S ribossomal (Lambert 2005). Essa resistência é determinada por um conjunto de pequenos genes, erithromicin ribosome methylase (ermA, B e C) que estão amplamente distribuídos, tanto em infecções estafilocócicas humanas como em animais (Lodder et al. 1997).
0 gene $m s r A$ é um dos responsáveis pelo mecanismo de efluxo de antimicrobianos por uma bomba ATP-dependente, mantendo assim concentrações intracelulares abaixo do nível requerido para a ligação aos ribossomos (Nicola et al. 1998). A bomba de efluxo promove a extrusão de inúmeras classes de antimicrobianos de relevância clínica, como tetraciclina e macrolídeos (Bambeke et al. 2000).

Quanto ao mecanismo de produção de biofilme, destaca-se o locus ica, um conjunto de quatro genes organizados em um operon (icaADBC) responsável pela expressão de uma adesina intercelular polissacarídica (PIA) ou de N-acetilglicosamina polimérica (PNAG). A co-expressão dos genes icaA e icaD é fundamental para a síntese completa do biofilme (O' Gara, 2007). Este tipo de organização é extremamente vantajosa a todas as espécies de micro-organismos, por fornecer proteção contra adversidades como desidratação, colonização por bacteriófagos e favorecer resistência a antimicrobianos (Gilbert et al. 2003).

No presente estudo, objetivou-se avaliar a suscetibilidade aos principais antimicrobianos e realizar uma caracterização fenotípica e genotípica de isolados de Staphylococcus spp. obtidos de casos de mastite em vacas e búfalas.

\section{MATERIAL E MÉTODOS}

\section{Isolamento bacteriano e identificação}

Foram utilizados 60 isolados de Staphylococcus spp. provenientes do Distrito Federal e cidades do entorno, obtidos de casos de mastite clínica e subclínica em vacas $(\mathrm{n}=30)$ e búfalas $(\mathrm{n}=30)$. Os 60 Staphylococcus spp. foram semeados em TSA (Tryptone Soya Agar), incubados a $37^{\circ}$ por 24 horas para posterior identificação bioquímica segundo Quinn et al. (1994).

\section{Teste de suscetibilidade aos antimicrobianos}

0 perfil de suscetibilidade das amostras foi determinado pelo método de disco-difusão Kirby-Bauer modificado (CLSI, 2006). Os isolados foram inoculados em Caldo Müeller Hinton, incubados a $37^{\circ} \mathrm{C}$ por duas horas e a turvação do caldo ajustada na escala 0,5 de Mac Farland. Com auxílio de um swab, os isolados foram semeados em placas de Petri contendo Ágar Mueller Hinton (MH). Logo após, foram aplicados os discos impregnados com as drogas antimicrobianas: gentamicina $(5 \mu \mathrm{g})$, estreptomicina $(10 \mu \mathrm{g})$, neomicina $(30 \mu \mathrm{g})$, eritromicina $(10 \mu \mathrm{g})$, penicilina $(10 \mu \mathrm{g})$, ampicilina (10 $\mu \mathrm{g})$, enrofloxacina $(5 \mu \mathrm{g})$, tetraciclina $(30 \mu \mathrm{g})$, sulfazotrim $(25 \mu \mathrm{g})$ e cefalexina $(30 \mu \mathrm{g})$. As placas foram incubadas em estufa durante $24 \mathrm{~h}$ a $37^{\circ} \mathrm{C}$. Após a leitura dos halos, as amostras foram classificadas como resistentes, sensíveis e de sensibilidade intermediária. 0 índice de resistência múltipla aos antimicrobianos (IRMA) foi calculado conforme metodologia descrita por Kruperman (1983), sendo este índice determinado pela relação entre o número de antimicrobianos que a amostra foi resistente e o número total de antimicrobianos testados.

\section{PCR para os genes icaD, mecA, blaZ, ermA, B, C e msrA}

A detecção dos genes de resistência, mecA, blaZ, icaD, msrA e emrA, B e C foi realizada segundo Greco et al. (2008), Murakami et al. (1991) e Sawant et al. (2009). Quatro microlitros (4 $\mu \mathrm{l}$ ) do DNA termoextraído (Medeiros et al. 2011) foram adicionados a $21 \mu \mathrm{l}$ de mix contendo 4 pmol de cada primer, $0.4 \mathrm{mM}$ de dNTPs, $1 \mathrm{U}$ de Taq DNA polimerase (Ludwig- Biotec), tampão (10mM Tris- $\mathrm{HCl}$ [pH 8.5] e 50mM KCl) e $2 \mathrm{mM} \mathrm{MgCl}_{2}$. O DNA de um Staphylococcus aureus meticilina resistente (MRSA) foi usado como controle positivo. A amplificação esperada para cada gene foi de: 249 pb (icaD), 
$214 \mathrm{bp}(\mathrm{mecA}), 517 \mathrm{bp}($ blaZ), $486 \mathrm{bp}(\mathrm{ermA}), 423 \mathrm{bp}(\mathrm{ermB}), 272$ bp (ermC) e $1000 \mathrm{bp}(\mathrm{msrA})$. Um volume de $20 \mu \mathrm{l}$ dos produtos da PCR foi submetido a uma corrida em gel de agarose a 1,5\% corado com brometo de etídeo $(0,5 \mu \mathrm{g} / \mathrm{mL})$ e observado sob luz ultravioleta.

\section{Detecção fenotípica de Bomba de Efluxo}

Os isolados de Staphylococcus spp. foram semeados em Ágar Müeller Hinton contendo a concentração de $0,5 \mu \mathrm{g} / \mathrm{ml}$ de brometo de etídeo. Após incubação das placas em estufa a $37^{\circ} \mathrm{C}$ por 24 horas, realizou-se a leitura em transiluminador sob luz ultravioleta. Colônias que não apresentaram fluorescência foram consideradas positivas para bomba de efluxo conforme descrições de Bjorland et al. (2005).

\section{Caracterização fenotípica da produção de biofilme utilizando Ágar Vermelho Congo (CRA)}

A produção de biofilme foi verificada segundo método descrito por Greco et al. (2008). As amostras foram semeadas em Ágar Vermelho Congo e após incubação das placas a $37^{\circ} \mathrm{C}$ por $24-48$ horas, colônias produtoras de biofilme apresentaram coloração negra. Amostras que demonstraram colônias com cores vermelhas a bordô foram consideradas sem a capacidade de produzir essa estrutura (Arciola et al. 2002).

\section{Caracterização fenotípica da produção de biofilme pelo teste de aderência em placas}

As bactérias foram cultivadas em TSB (Tryptone Soya Broth) por 24 horas a $37^{\circ} \mathrm{C}$. Logo após, uma porção de cada cultivo foi diluída à 1:40 em TSB adicionado de $0,25 \%$ de glicose. Cada amostra, já padronizada, foi colocada em placas de hemaglutinação com 96 cavidades com fundo em "U", em triplicata, junto com controles, no volume de $200 \mu \mathrm{L} /$ cavidade. Após o período de incubação $\left(37^{\circ} \mathrm{C}\right.$ por $\left.24 \mathrm{~h}\right)$, as placas foram lavadas três vezes com água destilada, e deixadas secar a temperatura ambiente. Foram adicionados $200 \mu \mathrm{L}$ de cristal violeta/cavidade, e a placa foi incubada por 2-3 minutos à temperatura ambiente. Após, cada cavidade foi lavada três vezes com água destilada e acrescida de álcool-acetona (80:20). As placas coradas com cristal violeta foram submetidas à espectrofotometria para aferir as respectivas absorbâncias de cada cavidade (Cucarella et al. 2001). Os isolados foram classificados em três categorias: não aderente, densidade óptica igual ou menor que 0,111 , fracamente aderente, densidade óptica maior que 0,111 e igual ou menor que 0,222 e fortemente aderente, densidade óptica maior que 0,222 .

\section{Análise estatística}

Empregou-se a técnica de estatística descritiva por meio da distribuição das frequências relativa e absoluta para os achados microbiológicos. Para o cálculo da concordância entre as provas realizadas utilizou-se o índice Kappa com auxílio do programa computacional WIN EPISCOPE 2.0 (Thrusfield 2004).

\section{RESULTADOS}

Dos trinta Staphylococcus isolados de casos de mastite bubalina, onze $(36,7 \%)$ foram identificados como S. hyicus, oito $(26,7 \%)$ como $S$. aureus, seis $(20,0 \%)$ como $S$. intermedius e cinco $(16,6 \%)$ como Staphylococcus coagulase positivo. Das amostras bovinas, nove $(30,0 \%)$ foram identificadas como $S$. intermedius, nove $(30,0 \%)$ como $S$. coagulase positivos, sete $(23,3 \%)$ como $S$. aureus e cinco $(16,7 \%)$ como $S$. hyicus. 0 percentual de sensibilidade das amostras bubalinas aos antimicrobianos foi: 100,0\% para enroflo- xacina, cefalexina e gentamicina, 90,0\% para eritromicina, $86,7 \%$ para tetraciclina, $83,3 \%$ para estreptomicina, $80,0 \%$ para penicilina e neomicina e $76,7 \%$ para sulfazotrim e ampicilina. As amostras bovinas apresentaram o seguinte perfil de sensibilidade: $96,7 \%$ para enrofloxacina e cefalexina, 93,3\% para gentamicina, 86,7\% para eritromicina, 83,3\% para sulfazotrim, $80,0 \%$ para neomicina, $73,3 \%$ para penicilina, 70,0\% para estreptomicina e $66,7 \%$ para tetraciclina e ampicilina. 0 índice de resistência múltipla aos antimicrobianos (IRMA) variou entre 0 e 0,5 . Vinte e quatro isolados (40,0\%), 14 bubalina e dez bovina, apresentaram sensibilidade a todos os antimicrobianos testados. Das quinze amostras identificadas como S. aureus, seis (40,0\%) apresentaram sensibilidade a todos os antimicrobianos.

Na pesquisa de genes de resistência, para o gene $m s r A$, um dos responsáveis pelo mecanismo de efluxo, duas $(6,7 \%)$ amostras de cada espécie foram consideradas positivas. Nenhuma das amostras de $S$. aureus foi considerada positiva para esse mecanismo de resistência. A amplificação na PCR dos genes mecA e blaZ foi observada, respectivamente, em uma $(3,3 \%)$ e seis $(20,0 \%)$ amostras de búfalas, e em bovinos, três $(10,0 \%)$ apresentaram amplificação para o gene mecA e uma $(3,3 \%)$, para o blaZ.

Os resultados obtidos no teste fenotípico para detecção de bomba de efluxo demonstraram cinco $(16,7 \%)$ amostras bubalinas positivas, sendo que quatro $(13,3 \%)$ apresentaram resistência à tetraciclina e uma à eritromicina $(3,3 \%)$. Por outro lado, onze $(36,7 \%)$ amostras bovinas foram consideradas positivas para bomba de efluxo, sendo que três $(10,0 \%)$ foram resistentes à tetraciclina e nenhuma à eritromicina. A concordância entre o teste fenotípico e genotípico ocorreu em $50 \%$ das amostras, com índice $\mathrm{ka}$ ppa igual a 0,10, sensibilidade de 50,0\% e especificidade de $75,0 \%$.

Quanto à pesquisa de biofilme, observou-se a presença do gene icaD em dois isolados de $S$. aureus bubalino e em três $S$. intermedius ( 2 bovinos e 1 bubalino). No teste realizado no Ágar Vermelho Congo (CRA), 20,0\% das amostras bubalinas e $26,7 \%$ das amostras bovinas foram positivas para produção de biofilme. O S. aureus, apresentou essa característica em cinco $(33,0 \%)$ dos seus isolados. No outro teste fenotípico para detecção de biofilme, o teste de Aderência em Placa, 13 (43,3\%) isolados bubalinos foram classificados como não aderidos, 9 (30,0\%) como fracamente aderidos e oito (26,7\%) como fortemente aderidos, totalizando $17(56,7 \%)$ isolados positivos para a formação de biofilme. Das amostras bovinas, 17 (56,7\%) foram classificadas como não aderidas, 10 (33,3\%) fracamente aderidas e três $(10,0 \%)$ fortemente aderidas, totalizando $13(43,3 \%)$ positivas e $17(56,7 \%)$ negativas para biofilme. Sete $(46,7 \%)$ S. aureus foram positivos para a produção de biofilme na técnica de Aderência em Placa.

Com relação aos testes de concordância realizados entre a PCR (gene icaD) e o teste no Ágar Vermelho Congo, observou-se um índice Kappa de -0,14, especificidade de $74,5 \%$ e uma sensibilidade nula. Na comparação entre a PCR (gene icaD) e o teste de Aderência em Placa, observouse um índice Kappa de 0,12, especificidade de $80 \%$ e uma sensibilidade igual a $40 \%$. 


\section{DISCUSSÃO E CONCLUSÕES}

Na espécie bubalina, observou-se maior frequência de Staphylococcus coagulase negativo (SCN). Estas espécies isoladas nesse estudo são amplamente relatadas como causadoras de mastite em fêmeas bubalinas no Brasil (Cunha et al. 2006) e no mundo (Saini et al. 1994, Lazzari et al. 2002). Na espécie bovina, também observou-se maior frequência de SCN, corroborando com vários estudos realizados no Brasil (Almeida et al. 2005, Medeiros et al. 2009, Oliveira et al. 2011) e no mundo (Waage et al. 1999, De Vliegher et al. 2012). A maior prevalência de $S C N$ neste estudo pode estar relacionada com as precárias condições de higiene nos locais de ordenha e das mãos do ordenhador.

Quanto ao perfil de sensibilidade aos antimicrobianos, observou-se que $40,0 \%$ dos isolados identificados como Staphylococcus aureus apresentaram resistência a todos os antimicrobianos. Rabello et al. (2005) encontraram 45,0\% dos $S$. aureus isolados de casos de mastite, com sensibilidade para todos os antimicrobianos testados. Essa discrepância é passível de ocorrer devido diferentes regiões geográficas estudadas e consequentemente as condições de criação, manejo e programas terapêuticos aos quais os animais são submetidos. Por outro lado, a alta sensibilidade encontrada para gentamicina, tanto nas amostras obtidas de vacas como de búfalas, foi demonstrada também por Kaszanyitzky et al. (2004). Vários trabalhos mencionam a eficácia da gentamicina no tratamento de mastite estafilocócica (Costa et al. 2000, Brito et al. 2001, Oliveira et al. 2002, Byarugaba et al. 2004), porém Freitas et al. (2005), verificaram o elevado nível de resistência dos estafilococos a esse antimicrobiano em regiões onde o fármaco era mais utilizado.

A tetraciclina é amplamente utilizada no tratamento das mastites e assim como no presente trabalho apresentou boa eficiência in vitro para estafilococos isolados de casos de mastite bovina em São Paulo (Cruz et al. 1998) e em Minas Gerais (Brito et al. 2001). Neste estudo, a tetraciclina apresentou uma eficiência igual a $86,7 \%$ sobre as amostras oriundas de fêmeas bubalinas e de $66,7 \%$ para amostras provenientes de isolados bovinos (66,7\%). A ampicilina, um derivado da penicilina, foi o antimicrobiano com o menor percentual de atuação tanto nas amostras bubalinas $(76,7 \%)$, quanto bovinas $(66,7 \%)$. Observa-se que assim como a tetraciclina, a ampicilina apresentou uma melhor atuação sobre as bactérias isoladas de mastite bubalina. Essa diferença de atuação pode ser provocada pela ampla utilização desses fármacos em infecções presentes em bovinos, resultando no uso indiscriminado do medicamento e contribuindo para seleção de cepas resistentes (Medeiros et al. 2009). Além disso, tem-se a eficiência da resistência plasmidial por meio da transferência de genes, resultando quase sempre, na produção de enzimas. Com relação à tetraciclina, tem-se a produção da proteína Tet, que é responsável pelo transporte deste antibiótico para fora da célula bacteriana (Souza 1998). De acordo com Vintov et al. (2003), 90,0\% dos S. aureus isolados de infecções em humanos, apresentam resistência à penicilina, enquanto em bovinos essa resistência pode variar de $10-70 \%$ de acordo com a localização geográfica. No presente trabalho o per- centual de resistência à ampicilina e penicilina, para todas as espécies de Staphylococcus, foi de $30,0 \%$ e para os S. aureus foi de 33,3\%. Esses percentuais encontram-se dentro dos limites descritos pelos últimos autores.

Em um isolado de $S$. aureus (bubalino) foi detectado o gene blaZ e em dois (bovino) o gene mecA. Essas duas últimas cepas são consideradas MRSA, pois o gene mecA está localizado em um componente genético chamado de SCCmec - Staphylococcal Cassete Cromossomal mec ou Cassete Cromossomal mec de Staphylococcus (SCCmec) composto de 20-65 Kb, integrado ao cromossomo de MRSA (Katayama et al. 2000).

Apesar de se esperar um maior número de isolados bubalinos resistentes aos beta-lactâmicos (pela maior detecção de genes de resistência), as amostras bovinas apresentaram maior resistência à ampicilina, cefalexina e penicilina. Sugere-se, que o maior uso de antimicrobianos em bovinos possa desencadear este fenômeno, baseando-se no estudo realizado por Garcia et al. (2004) que mencionam que nas bactérias Gram-positivas a enzima beta-lactamase é produzida apenas na presença de indutores, como a penicilina. A proteína PBP-2A, também pode ser induzida pela presença de beta-lactâmicos ou pode ser produzida de forma constitutiva. Ela é indutível em cepas que possuem o plasmídio responsável pela produção de beta-lactamase e constitutiva quando os mesmos estão ausentes (Matsuhashi et al. 1986).

Pelo teste fenotípico para detecção de bomba de efluxo, detectaram-se dezesseis amostras positivas, sendo cinco $(16,7 \%)$ provenientes de amostras bubalinas e onze $(36,7 \%)$ de amostras bovinas. Essa diferença pode ser explicada pela maior expressão dos genes de resistência em isolados oriundos de fêmeas bovinas, devido ao uso mais frequente de antimicrobianos nesta espécie. A bomba de efluxo é um dos três mecanismos de resistência apresentado tanto para tetraciclinas como para os macrolídeos. Esse mecanismo é realizado por transportadores localizados na membrana que funcionam com energia fornecida pelo ATP e pela força próton motiva (Putman et al. 2000). Outro mecanismo de resistência a macrolídeos se baseia na modificação do ribossomo por metilação. Dos genes erm, responsáveis pela metilação e dimetilação do ribossomo, apenas o B foi encontrado em um $S$. aureus isolado de bovino. Wang et al. (2008) encontraram em S. aureus isolados de mastite bovina os genes ermB e C, já Almer et al. (2002), observaram que o gene ermA foi mais prevalente em MRSA humanos, sem detecção do gene ermB. 0 percentual de resistência aos macrolídeos e tetraciclina, detectados pelo teste de disco-difusão, foi superior ao encontrado nos testes de bomba de efluxo e PCR (detecção de genes erm). Esta diferença pode ser consequência de outro mecanismo de resistência, como a produção da enzima metilase (Gatermann et al. 2007), que não foi pesquisada no presente trabalho.

Na pesquisa de biofilme, por meio do teste Ágar Vermelho Congo (CRA), $20 \%$ das amostras bubalinas e $26,7 \%$ das amostras bovinas foram positivas. No teste de Aderência em Placa, $56,6 \%$ dos isolados bubalinos e $43,3 \%$ dos isolados bovinos foram positivos para a formação de biofilme. Resultados similares foram obtidos por Melo (2008) que 
relatou ser o teste de Aderência em Placa mais sensível que o CRA. Ainda de acordo com este autor os resultados falso-negativos no CRA ocorrem devido à fase de variação na produção do biofilme. Observou-se um índice Kappa de 0,12 para comparação entre a PCR (gene icaD) e o teste de Aderência em Placa e de -0,14 para o CRA. Isto demonstra uma baixa concordância entre os métodos fenotípicos e genotípicos, devendo-se ter cautela na interpretação destes resultados. As divergências podem estar associadas à subjetividade das provas fenotípicas, tendo em vista que a produção in vitro do biofilme bacteriano pode ser influenciada por diferentes condições de crescimento e mecanismos de aderência (Oliveira et al. 2006). Quanto à PCR, sabe-se que outros marcadores genéticos não testados neste trabalho estão relacionados com a formação dessas estruturas, como os genes icaA e bap (biofilm associated protein) (Vasudevan et al. 2005). Tormo et al. (2005) observaram que os isolados estafilocócicos que continham o gene bap eram fortes produtores de biofilme, apesar da maioria deles não conter o locus ica. Apesar disso, tem sido relatada baixa prevalência deste gene em Staphylococcus spp. isolados de mastite (Cucarella et al. 2001).

Segundo Wuertz et al. (2004) a água é o principal componente do biofilme. Ela circula entre as estruturas, permitindo a maior aquisição e troca de genes por transferência horizontal. Com base nisso, pode-se sugerir que os isolados bubalinos, por possuírem maior número de cepas produtoras de biofilme no teste de Aderência em Placa e na PCR para o gene icaD, são agentes com maior potencial de disseminação de material genético do que os isolados bovinos.

0 biofilme é conhecido pela sua capacidade de isolar a bactéria em uma matriz polissacarídica, impedindo, muitas vezes, a ação de antimicrobianos (Gilbert et al. 2003). Baselga et al. (1993), Fox et al. (2005) e Oliveira et al. (2006), estudaram a formação de biofilme por isolados de S. aureus, através do método Ágar Vermelho Congo, e verificaram resultados semelhantes aos descritos no presente estudo. Vasudevan et al. (2003), utilizando o mesmo método, encontraram $91,4 \%$ das estirpes de $S$. aureus produtoras de biofilme. Knobloch et al. (2002) descreveram a baixa confiabilidade do CRA como método diagnóstico em amostras de S. aureus. Vasudevan et al. (2003), encontraram $68,6 \%$ das estirpes positivas para biofilme, pelo método de Aderência em Placas. Fox et al. (2005) ao estudarem S. aureus isolados de leite, pele do teto e insufladores, detectaram uma produção de biofilme, pelo método de Aderência em Placa, de $41 \%, 24,7 \%$ e $14,7 \%$, respectivamente. Stepanovic et al. (2000) notaram que o teste de Aderência em Placas é um dos métodos utilizados com maior frequência para quantificar a formação dos biofilmes produzidos por Staphylococcus spp., além de funcionar como um indicador de patogenicidade dos micro-organimos. A presença do gene icaD foi observada em dois $S$. aureus bubalino e três $S$. intermedius ( 2 bovinos e 1 bubalino). Arciola et al. (2001) detectaram o gene ica $\mathrm{D}$ em $61,0 \%$ dos isolados, enquanto Fowler et al. (2001) encontraram o mesmo gene em todas as amostras pesquisadas. Neste trabalho, nenhuma amostra foi positiva para o gene icaD e CRA simultaneamente e quatro amostras foram positivas para icaD e o teste de Aderência em Placa.

\section{CONCLUSÃO}

Observou-se que os isolados obtidos de amostras bovinas apresentaram uma menor sensibilidade aos antimicrobianos no teste de disco-difusão quando comparados com as amostras bubalinas. Estes estudos de sensibilidade permitem orientar uma antibioticoterapia bem planejada. A presença de biofilme nos isolados pode estar associada a outros fatores que não a resistência às drogas antimicrobianas. Os estudos de caracterização molecular dos principais patógenos da mastite são fundamentais para esclarecer aspectos referentes da epidemiologia da enfermidade e, dessa forma, subsidiar as ações de um programa de controle e prevenção da doença.

\section{REFERÊNCIAS}

Almeida A.C., Mendes C.P.A. \& Silva D.B. 2005. Fatores determinantes da ocorrência de mastite bovina, detectada em rebanhos através da análise de leite em latões. Revta Higiene Alimentar 19(134):81-87.

Almer L.S., Shortridgea V.D., Niljusa A.M., Beyera J.M., Sonia N.B., Buia M.H., Stoneb G.G. \& Flamma R.K. 2002. Antimicrobial susceptibility and molecular characterization of community-acquired methicillin-resistant Staphylococcus aureus. Diagnostic Microbiol. Infect. Dis. 43:225-232.

Arciola C.R., Baldassarri L. \& Montanaro L. 2001. Presence of icaa and icad genes and slime production in a collection of staphylococcal strains from catheter associated infections. J. Clin. Microbiol. 39:2151-2156.

Arciola C.R., Campoccia D., Gamberini S., Cervellati M., Donati E. \& Montanaro L. 2002. Detection of slime production by means of an optimised congo red agar plate test based on a colourimetric scale in Staphylococcus epidermidis clinical isolates genotyped for ica locus. Biomaterials 23:4233-4239.

Bambeke V.F., Balzi E. \& Tulkens P.M. 2000. Antibiotic efflux pumps. Biochem. Pharmacol. 60:457-70.

Baselga R., Albizu I., De La Cruz M., Del Cacho E., Barberan M. \& Amorena B. 1993. Phase variation of slime production in staphylococcus aureus: implications in colonization and virulence. Infect. Immun. 61:4857-4862.

Bignardi G.E., Woodford N., Chapman A., Johnson A.P. \& Speller D.C.E. 1996. Detection of the mec-a gene and phenotypic detection of resistance in Staphylococcus aureus isolates with borderline or low-level methicillin resistance. J. Antim Chemother. 37:53-63.

Bjorland J., Steinum T., Kvitle B., Waage S., Sunde M. \& Heir E. 2005. Widespread distribution of disinfectant resistance genes among Staphylococci of bovine and caprine origin in Norway. J. Clin. Microbiol. 43(9):4363-4368.

Brito M.A.V.P., Brito J.R.F., Silva M.A.S. \& Carmo R.A. 2001. Concentração mínima inibitória de dez antimicrobianos para amostras de Staphylococcus aureus isoladas de infecção intramamária bovina. Arq. Bras. Med. Vet. Zootec. 53(5):531-537.

Byarugaba D.K. 2004. A view on antimicrobial resistance in developing countries and responsible risk factors. J. Antimicrobiol. Agents 24:105-110.

CLSI 2006. Performance standards for antimicrobial susceptibility testing. $16^{\text {th }}$ Informational Supplement, Document M100-S16. Wayne, Pennsylvania.

Costa E.O., Benites N.R., Thiers F.O., Ribeiro A.R., Garino Jr F. \& Silva J.A. 2000. Escore de CMT em relação ao nível de células somáticas em leite do tanque de refrigeração e percentual de mastite subclínica em propriedades leiteiras de São Paulo e minas gerais. Revta Napgama 3:14-18.

Cruz A.D., Batista G.C.M., Modolo J.R., Gott S.A.F. \& Lopes C.A.M. 1998. Atividade in vitro do danofloxacin e de sete drogas antimicrobianas frente a linhagens de Staphylococcus aureus isoladas de mastite bovina. Arq. Bras. Med. Vet. Zootec. 50(4):369-373.

Cucarella C., Solano C., Valle J., Amorena B., Lasa I. \& Penade's J.R. 2001. Bap, a Staphylococcus aureus surface protein involved in biofilm formation. J. Bacteriol. 183:2888-2896.

Cunha A.P., Silva L.B.G., Pinheiro Junior J.W., Silva D.R., Oliveira A.A., Silva K.P.C. \& Mota R.A. 2006. Perfil de sensibilidade antimicrobiana de agentes contagiosos e ambientais isolados de mastite clinica e subclínica de búfalas. Arqs Inst. Biológico, São Paulo, 73:17-21. 
De Vliegher S., Fox L.K., Piepers S., McDougall S. \& Barkema H.W. 2012. Invited review: Mastitis in dairy heifers: nature of the disease, potential impact, prevention, and control. J. Dairy Sci. 95(3):1025-1040.

Fowler V.G., Fey P.D., Reller L.B., Chamis A.L., Corey G.R. \& Rupp M.E. 2001. The intercellular adhesin locus ica is present in clinical isolates of Staphylococcus aureus from bacteremic patients with infected and uninfected prosthetic joints. Med. Microbiol. Immunol. 189:127-131.

Fox L.K., Zadoks N.R. \& Gaskins T.C. 2005. Biofilm production by Staphylococcus aureus associated with intramammary infection. Vet. Microbiol. 107:295-299.

Freitas M.F.L., Pinheiro Jr J.W., Stamford T.L.M., Rabelo S.S.A., Silva D.R., Silveira Filho V.M.S., Santos F.G.B., Sena M.J. \& Mota R.A. 2005. Perfil de sensibilidade antimicrobiana in vitro de Staphylococcus coagulase positivos isolados de leite de vacas com mastite no agreste do estado de Pernambuco. Arqs Inst. Biológico, São Paulo, 72(2):171-177.

Garcia C.R., Mallorqui F.G., Marrero A., Potempa J., Coll M. \& Gomis R. 2004. On the transcriptional regulation of methicillin resistance: meci repressor in complex with its operator. J. Biol. Chem. 279:17888-17896.

Gatermann S.G., Koschinski T. \& Friedrich S. 2007. Distribution and expression of macrolide resistance genes in coagulase-negative Staphylococci. Clin. Microbiol. Infect. 13:777-781.

Gilbert P., McBain A.J. \& Rickard A.H. 2003. Formation of microbial biofilm in hygienic situations: a problem of control. Int. Biodeterior. Biodegrad. 51(4):245-248.

Greco C., Mastronardi C., Pagotto F., Mack D. \& Ramirez-Arcos S. 2008. Assessment of biofilm-forming ability of coagulase-negative Staphylococci isolated from contaminated platelet preparations in Canada. Transfusion 48:969-977.

Ito T., Okuma K., Ma X.X., Yuzawa H. \& Hiramatsu K. 2003. Insights on antibiotics resistance of Staphylococcus aureus from its whole genome: genomic island. Drug Resistance Updates 6(1):41-52.

Kaszanyitzky E.J., Egyed Z., Jánosi S., Keseru J., Szabó I., Veres Z. \& Somogyi P. 2004. Staphylococci isolated from animals and food with phenotypically reduced susceptibility to beta-lactamase-resistant beta-lactam antibiotics. Acta Vet. Hung. 52(1):7-17.

Katayama Y., Ito T. \& Hiramatsu K. 2000. A new class of genetic element, Staphylococcus Cassette Chromosome mec, encodes methicillin resistance in Staphylococcus aureus. Antimicrob. Agents Chemother. 44:1549-1555.

Knobloch J.K.M., Horstkotte M.A., Rohde H. \& Mack D. 2002. Evaluation of different detection methods of biofilm formation in Staphylococcus aureus. Med. Microbiol. Immunol. 191(2):101-106.

Krumperman P.H. 1983. Multiple antibiotic resistance indexing of Escherichia coli to identify high-risk sources of fecal contamination of foods. Appl. Environ. Microbiol. 46(1):165-170.

Lambert P.A. 2005. Bacterial resistance to antibiotics: modified target sites. Adv. Drug Delivery Revs 57:1471-1485.

Lazzari A.M., Silva A.M., Oliveira M.V.S., Corbucci V., Oliveira P.R.M.A., Ferraz C.N., Proença L.M., Bianchi R.G. \& Weiler C.A. 2002. Bubaline mastitis (Bubalus bubalis): comparison of California Mastitis Test (CMT) and Whiteside (WS) with microbiological isolation of milk, preliminary report. Annals XXI World Buiatrics Congress, Hannover, Germany.

Li X.Z., Mehrotra M., Ghimire S. \& Adewoye L. 2007. $\beta$-lactam resistance and beta-lactamases in bacteria of animal origin. Vet. Microbiol. 121(3/4):197-214.

Lodder G., Werckenthin C., Schwarz S. \& Dyke K. 1997. Molecular analysis of naturally occurring ermc-encoding plasmids in Staphylococci isolated from animals with and without previous contact with macrolide/lincosamide antibiotics. Immunol. Med. Microbiol. 18:7-15.

Matsuhashi M., Song M.D., Ishino F., Wachi M., Doi M., Inoue M., Ubukata K., Yamashita N. \& Konno M. 1986. Molecular cloning of the gene of a penicillin-binding protein supposed to cause high resistence to $\beta$-lactam antibiotics in Staphylococcus aureus. J. Bacteriol. 167:975:980.

Medeiros E.S., Mota R.A., Santos M.V., Freitas M.F.L., Pinheiro Jr J.W. \& Teles J.A.A. 2009. Perfil de sensibilidade microbiana in vitro de linhagens de Staphylococcus spp. isoladas de vacas com mastite subclínica. Pesq. Vet. Bras. 29(7):569-574.

Medeiros E.S., França C.A., Krewer C.C., Peixoto R.M., Junior A.S.F., Cavalcante M.B., Costa M.M. \& Mota R.M. 2011. Antimicrobial resistance of
Staphylococcus spp. isolates from cases of mastitis in Buffalo in Brazil. J. Vet. Diagn. Invest. 23(4):793-796.

Melo P.C. 2008. Estudo fenotípico e genotípico da produção de biofilmes por estirpes de Staphylococcus aureus isoladas dos casos de mastite subclínica bovina. Dissertação de Mestrado em Medicina Veterinária Preventiva, Faculdade de Ciências Agrárias e Veterinárias, Universidade Estadual Paulista, Jaboticabal, SP. 122p.

Murakami K.W., Minamide W., Wada K., Nakamura E., Teraoka H. \& Watanabe S. 1991. Identification of methicillin resistant strains of Staphylococci by polymerase chain reaction. J. Clin. Microbiol. 29:2240-2244.

Nicola F.G., McDougal L.K., Biddle J.W. \& Tenover F.C. 1998. Characterization of erythromycin-resistant isolates of Staphylococcus aureus recovered in the United States from 1958 through 1969. Antimicrob. Agents Chemother. 42:3024-3027.

0'Gara J.P. 2007. Ica and beyond: biofilm mechanisms and regulation in Staphylococcus epidermidis and Staphylococcus aureus. Fems Microbiol. Letters 270(2):179-188.

Oliveira A.A.F., Mota R.A., Souza M.I. \& Sá M.E.P. 2002. Perfil de sensibilidade antimicrobiana in vitro frente a amostras de Staphylococcus spp. isolados de mastite subclínica bovina, no agreste meridional de Pernambuco. Hora Vet. 22(127):8-10.

Oliveira M., Bexiga R., Nunes S.F., Carneiro C., Cavaco L.M., Bernardo F. \& Vilela C.L. 2006. Biofilm-forming ability profiling of Staphylococcus aureus and Staphylococcus epidermidis mastitis isolates. Vet. Microbiol. 118:133-140.

Oliveira C.M.C., Sousa M.G.S., Silva N.S., Mendonça C.L., Silveira J.A.S., Oaigen R.P., Andrade S.J.T. \& Barbosa J.D. 2011. Prevalência e etiologia da mastite bovina na bacia leiteira de Rondon do Pará, estado do Pará. Pesq. Vet. Bras. 31(2):104-110.

Putman M., Veen H.M.V. \& Konings W.N. 2000. Molecular properties of bacterial multidrug transporters. Microbiol. Mol. Biol. Revs 64(4):672-693.

Quinn P.J., Carter M.E., Markey B. \& Carter G.R. 1994. Clinical Veterinary Microbiology. Wolfe, Virginia. 647p.

Rabello R.F., Souza C.R., Duarte R.S., Lopes R.M., Teixeira L.M. \& Castro D.A.C. 2005. Characterization of Staphylococcus aureus isolates recovered from bovine mastitis in Rio de Janeiro. J. Dairy Sci. 88:3211-3219.

Saini S.S., Sharma J.K. \& Kwatra M.S. 1994. Prevalence and etiology of subclinical mastitis among crossbred cows and buffaloes in Punjab. Indian J. Dairy Sci. 47(2):103-106.

Sawant A.A., Gillespie B.E. \& Oliver S.P. 2009. Antimicrobial susceptibility of coagulase-negative Staphylococcus species isolated from bovine milk. Vet. Microbiol. 134:73-81.

Souza E.C. 1998. Bactérias ultra-resistentes. Ciência Hoje 23(138):27-35.

Stepanovic S., Vukovic D., Dakic I., Savic B. \& Vlahovic M.S. 2000. A modified microtiter-plate test for quantification of Staphylococcus biofilm formation. J. Microbiol. Methods 40:175-179.

Thrusfield M.V. 2004. Epidemiologia Veterinária. 2ª ed. Roca, São Paulo. 556p.

Tormo M.A., Knecht E., Götz F., Lasa I. \& Penadés J.R. 2005. Bap-dependent biofilm formation by pathogenic species of Staphylococcus: evidence of horizontal gene transfer? Microbiol. 151:2465-2475.

Vasudevan P., Nair M.K.M., Annamalai T. \& Venkitanarayanan K.S. 2003. Phenotypic and genotypic characterization of bovine mastitis isolates of Staphylococcus aureus for biofilm formation. Vet. Microbiol. 92:179-185.

Vermelho A.B., Bastos M.C.F. \& Sá M.H.B. 2007. Bacteriologia geral. Guanabara Koogan, Rio de Janeiro, p.541-560.

Vintov J., Aarestrup F.M., Zinn C.E. \& Olsen J.E. 2003. Association between phage types and antimicrobial resistance among bovine Staphylococcus aureus from 10 countries. Vet. Microbiol. 95:133-147.

Waage S., Mork T., Roros A., Aasland D., Hunshamar A. \& Odgaard S.A. 1999. Bacteria associated with clinical mastitis in dairy heifers. J. Dairy Sci. 82(4):712-719.

Wang Y., Wu C.M., Lu L.M., Ren G.W.N.R., Cao X.Y. \& Shen J.Z. 2008. Macrolide-lincosamide-resistant phenotypes and genotypes of Staphylococcus aureus isolated from bovine clinical mastitis. Vet. Microbiol. 130:118-125.

Wuertz S., Okabe S. \& Hausner M. 2004. Microbial communities and their interactions in biofilm systems: an overview. Water Sci. Technol. 49:327336. 